\title{
Study on Leaf Function Traits of Typical Plants in Plantation of Shouguang National Wetland Park
}

\author{
Yifu Yuan ${ }^{1}$, Zhen Zhao ${ }^{1}$, An Mao ${ }^{1, ~ *, ~ Y u j i e ~ L u o ~}{ }^{2, *}$ \\ ${ }^{1}$ State Forestry and Grassland Administration Key Laboratory of Silviculture in downstream areas of the Yellow River, College of Forestry, \\ Shandong Agricultural University, Taian, China \\ ${ }^{2}$ Tourism School, Shandong Women's University, Jinan, China
}

\section{Email address:}

yuanyf16@163.com (Yifu Yuan), zhaozh9811@163.com (Zhen Zhao), dannymaoan@126.com (An Mao), yuaneco@sdau.edu.cn (Yujie Luo) ${ }^{*}$ Corresponding author

\section{To cite this article:}

Yifu Yuan, Zhen Zhao, An Mao, Yujie Luo. Study on Leaf Function Traits of Typical Plants in Plantation of Shouguang National Wetland Park. American Journal of Agriculture and Forestry. Vol. 8, No. 6, 2020, pp. 247-251. doi: 10.11648/j.ajaf.20200806.12

Received: November 5, 2020; Accepted: November 19, 2020; Published: November 23, 2020

\begin{abstract}
Plant functional traits reflect the influence of surrounding environment and adaptability to environmental changes. Plants growing on saline soil can adapt to this kind of stress by adjusting plant functional traits. In order to study the effect of saline environment on plant functional traits, we selected a plantation in a coastal park as the research object. We sampled trees, shrubs and grass layers, and analyzed the differences of leaf functional traits among different plants, and discussed the adaptive performance of plants to salinization stress through functional traits. In this study, ten species (Fraxinus chinensis, Ailanthus altissima, Sophora japonica, Populus tomentosa, Salix babylonica, Gleditsia sinensis, Tamarix chinensis, Sonchus oleraceus, Conyza Canadensis, Echinochloa crusgalli) were selected as the research objects to analyze their leaf area, leaf perimeter and leaf aspect ration, to explore the differences of functional traits among plants and their adaptation to saline environment. The results showed that the main leaf functional traits of $F$. chinensis remained stable in different forest ages, and significant differences were found in the leaf area and leaf aspect ration among different layers of plants.
\end{abstract}

Keywords: Functional Traits, Leaf, Soil Salinization, National Wetland Park, Fraxinus chinensis

\section{Introduction}

\subsection{Plant Functional Traits}

The long-term interaction between plant and environment has formed many physiological and morphological adaptive strategies, which are called plant functional traits [1-3]. Plant functional traits reflect the influence of the surrounding environment and the adaptability to environmental changes, and to a certain extent, have ecological indicators. Plant leaves play an important role in photosynthesis, transpiration and gas exchange. It provides energy for living things on earth, and is also essential for maintaining the function of the ecosystem. Leaf traits of plants refer to some life strategies of plant leaves under long-term interaction with external environment, mainly including structural and functional traits. Leaf structural traits refer to the structural characteristics related to leaves, which generally change little and are relatively stable, including leaf aspect ration, specific leaf area, single leaf weight, etc. Leaf functional traits are plant growth and metabolism indicators, and general functional traits change greatly, such as respiratory rate, photosynthetic rate, etc.

\subsection{Research Progress of Plant Functional Traits}

In recent years, advances have been made in the study of plant functional traits, such as the maintenance of plant traits and community structure, the relationship between traits and productivity, and so on. Intraspecific and interspecific variation of plant functional traits is the most widely studied content [4]. The distribution of plant functional traits in different scales is affected by different environmental factors. On the large scale, the distribution of plant traits is mainly affected by climate factors; on the small scale, the distribution of plant traits is mainly affected by terrain and soil factors [2, 5]. At the global scale, the most concerned plant functional 
traits are the leaf economic spectrum, which quantitatively analyzes the plant functional traits and their relationships at the global scale, and the resource trade-off strategy is the basis for the formation of the leaf economic spectrum [6].

\subsection{Effects of Soil Salinization on Plants}

Saline soil is a general term for various types of soil that contain excessive saline components, including saline soil, alkaline soil and other types of soil that have undergone a certain degree of salinization or alkalization [7]. There are about 6.7 million $\mathrm{hm}^{2}$ of saline land in China, mainly distributed in arid, semi-arid areas and coastal areas [8]. Salinized soil is easy to harden due to salt agglutination, and its permeability is poor, so it is not conducive to plant growth. Due to the lack of nutrients, the salinized soil is not growing well, which leads to the deficiency of plant elements, the poor air permeability of root system, the poor respiration and even the survival of plants. The other is the indirect effect on plants. Soil compaction leads to poor soil permeability, which makes the physiological activities of some organisms in the soil unable to carry out normally.

Plants growing on saline soil can adapt to this kind of stress by adjusting plant functional traits. Generally, salinization environment will reduce plant height, stem height and root length. In addition, photosynthesis of plants will also be affected, resulting in a decrease in photosynthetic rate $[9,10]$. Under saline stress, the decrease of leaf area and the damage of chloroplast structure will cause the decrease of photosynthetic rate. In the face of the stress of salinization, plants will adjust to better survive.

In order to study the effect of saline environment on plant functional traits, we selected a plantation in a coastal park as the research object. We sampled trees, shrubs and grass layers, and analyzed the differences of leaf function traits among different plants.

\section{Methods}

\subsection{Study Area}

Shouguang National Wetland Park is located in the coastal area of Laizhou Bay, in the north of Shandong Province. Its climate type belongs to warm temperate continental monsoon climate. The precipitation is mainly from June to September, and the annual average temperature is between $10^{\circ} \mathrm{C}$ and $20^{\circ} \mathrm{C}$. Some parts of the wetland park are easy to be invaded by sea water, resulting in the soil salinity reaching $3-8 \%$, which is salinized tidal soil. Under the long-term management and restoration, the plantation community dominated by Fraxinus chinensis has been formed [9].

\subsection{Field Investigation and Sample Collection}

In this study, according to the growth and distribution of plants, the suitable forest areas were selected, and the main dominant tree, shrub and grass species were sampled. We screened the 10 dominant plants in communities, including 6 tree species (Fraxinus chinensis, Ailanthus altissima, Sophora japonica, Populus tomentosa, Salix babylonica, Gleditsia sinensis), 1 shrub (Tamarix chinensis) and 3 grass plants (Sonchus oleraceus, Conyza canadensis, Echinochloa crusgalli). Five plants with good growth were selected for each plant, and the leaves with healthy physiological status were collected. The leaves of trees and shrubs selected on the outer branches of the crown. Put the leaves between two pieces of wet filter paper, put them into bags, take them back to the laboratory, and put them in the refrigerator fresh-keeping layer for storage.

Plant leaves were selected as experimental measurement samples, and these plant leaves were required to be relatively complete, uniform and moderate in size. Dust on the surface of the leaves was wiped with paper, and then the morphological and functional indexes were measured. The leaves were scanned by scanner, and the morphological characters of leaves were obtained by winfolia pro2009a (Regent instruments, Inc., Quebec, Canada).

\section{Results}

\subsection{Leaf Functional Traits of Main Plants in Plantation Community}

It can be seen from the table below that there are significant differences in the main leaf functional traits of these typical plants in the plantation community, which indicates that there are significant differences in the leaf morphology of these plants.

Table 1. Results of one-way ANOVA (F-values and significance levels) for leaf functional traits of different plants.

\begin{tabular}{lll}
\hline Traits & $\mathbf{F}$ & $\boldsymbol{p}$ \\
\hline Leaf area & 29.197 & $0^{* * *}$ \\
leaf perimeter & 10.429 & $0^{* * *}$ \\
Leaf vertical length & 13.078 & $0^{* * *}$ \\
Leaf avghorizontal width & 105.402 & $0^{* * *}$ \\
Leaf aspect ration & 6.478 & $0^{* * *}$ \\
\hline Significant effects are indicated by asterisks: ${ }^{* * *} p<0.001,{ }^{* *} p<0.01$ and \\
${ }^{*} p \leq 0.05$.
\end{tabular}

Populus tomentosa had the largest leaf area among the tree species, with an average of $26.81 \mathrm{~cm}^{2}$, while Gleditsia sinensis had the smallest leaf area $\left(5.44 \mathrm{~cm}^{2}\right)$; among grass plants, Sonchus oleraceus had the largest leaf area of $24.28 \mathrm{~cm}^{2}$, significantly larger than Echinochloa crusgalli and Conyza canadensis. The leaves of Tamarix chinensis are scaly, and the area of leaf is the smallest among all kinds of plants. Among the tree plants, the leaf perimeter of Ailanthus altissima is the largest, with an average of $27.55 \mathrm{~cm}$. Similar to the results of leaf area, the leaf perimeter of $G$. sinensis was also the smallest, which was $11.32 \mathrm{~cm}$; in grass plants, $S$. oleraceus and E. crusgalli were close to each other, $36.57 \mathrm{~cm}$ and 36.33 $\mathrm{cm}$ respectively, which was significantly larger than that of $C$. canadensis. Among tree plants, A. altissima had the largest leaf vertical length, with an average of $10.73 \mathrm{~cm}, G$. sinensis had the smallest, with a length of $4.35 \mathrm{~cm}$; among grass plants, E. crusgalli had the leaf vertical length of $14.37 \mathrm{~cm}$, while $S$. 
oleraceus had the smallest. Leaf avghorizontal width of $P$. tomentosa is the largest, which is $3.76 \mathrm{~cm}$, and Salix babylonica is the smallest, which is $0.92 \mathrm{~cm}$; among grasses, leaf avghorizontal width of S. oleraceus is the largest, which is $1.51 \mathrm{~cm}$, while that of E. crusgalli is the smallest, which is $0.74 \mathrm{~cm} ;$ T. chinensis is the smallest among all plants. The leaf aspect ration of $S$. babylonica was 5.28, which was significantly higher than that of other tree species. The leaf aspect ration of $P$. tomentosa was the smallest, which was 1.13; the leaf aspect ration of $C$. canadensis was the largest, 9.35, which was much higher than that of $S$. oleraceus.

Table 2. Leaf functional traits of different plants.

\begin{tabular}{llllll}
\hline Species & Leaf area $\left(\mathbf{c m}^{2}\right)$ & Leaf Perimeter $\mathbf{( c m )}$ & Leaf vertical length $(\mathbf{c m})$ & Leaf avghorizontal width $(\mathbf{c m})$ & Leaf aspect ration \\
\hline Fraxinus chinensis & $15.72 \pm 0.75$ & $18.87 \pm 0.56$ & $7.34 \pm 0.21$ & $2.06 \pm 0.06$ & $2.18 \pm 0.08$ \\
Ailanthus altissima & $23.40 \pm 1.41$ & $27.55 \pm 0.98$ & $10.73 \pm 0.37$ & $2.18 \pm 0.09$ & $3.06 \pm 0.09$ \\
Sophora japonica & $7.77 \pm 0.35$ & $12.39 \pm 0.34$ & $5.09 \pm 0.19$ & $1.51 \pm 0.07$ & $2.34 \pm 0.13$ \\
Salix babylonica & $8.47 \pm 1.02$ & $20.68 \pm 2.05$ & $8.69 \pm 0.87$ & $0.92 \pm 0.06$ & $5.28 \pm 1.17$ \\
Populus tomentosa & $26.82 \pm 1.53$ & $25.67 \pm 0.67$ & $7.55 \pm 0.41$ & $3.76 \pm 0.17$ & $1.13 \pm 0.03$ \\
Gleditsia sinensis & $5.44 \pm 0.67$ & $11.32 \pm 0.40$ & $4.35 \pm 0.24$ & $1.23 \pm 0.08$ & $2.43 \pm 0.08$ \\
Tamarix chinensis & $1.24 \pm 0.16$ & $19.94 \pm 3.11$ & $3.48 \pm 0.12$ & $0.37 \pm 0.05$ & $2.64 \pm 0.38$ \\
Sonchus oleraceus & $24.28 \pm 3.65$ & $36.57 \pm 3.55$ & $9.00 \pm 0.88$ & $1.51 \pm 0.13$ & $1.38 \pm 0.19$ \\
Conyza canadensis & $8.92 \pm 0.74$ & $27.38 \pm 0.89$ & $11.14 \pm 0.37$ & $0.80 \pm 0.07$ & $9.35 \pm 0.94$ \\
Echinochloa & $12.42 \pm 1.57$ & $36.33 \pm 4.67$ & $14.37 \pm 1.75$ & $0.74 \pm 0.07$ & $7.84 \pm 2.07$ \\
crusgalli & & & & \\
\hline
\end{tabular}

Values are presented as mean $\pm \mathrm{SD}$.

\subsection{Comparison of Leaf Functional Traits of F. Chinensis Plantation at Different Ages}

The area of $F$. chinensis plantation in Wetland Park is large, and we selected three $F$. chinensis communities. According to the stand age, it was divided into young forest and middle age forest. The leaf area and leaf aspect ration of $F$. chinensis, the two main leaf morphological characters, were different in different forest ages. The leaf area decreased gradually with the increase of stand age, and was the smallest in the middle age forest, but the difference was not significant among different ages. On the contrary, leaf aspect ration gradually increased with the increase of stand age, and reached the maximum at middle stand age, but the difference between groups was not significant. According to these two main leaf morphological characters, it can be seen that the leaf morphological traits of $F$. chinensis are relatively stable in young and middle-aged forests.

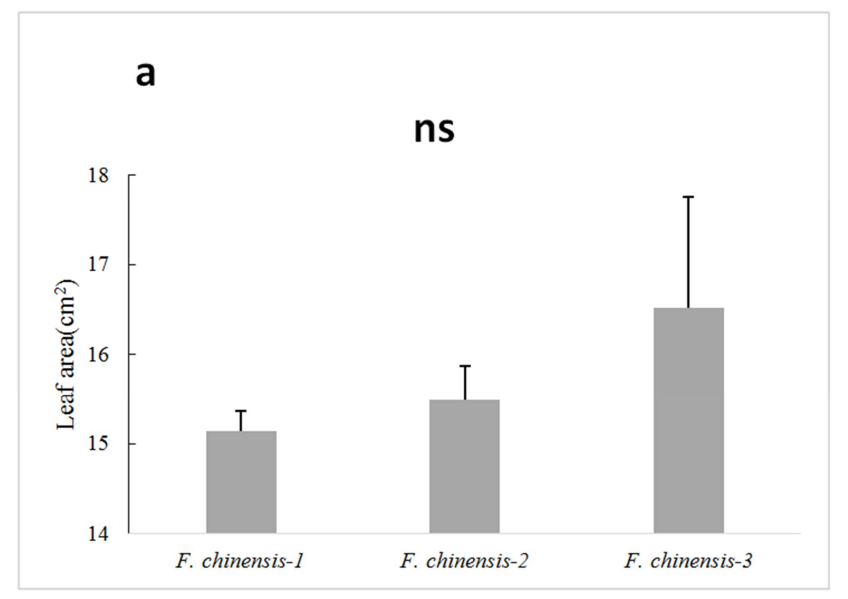

b

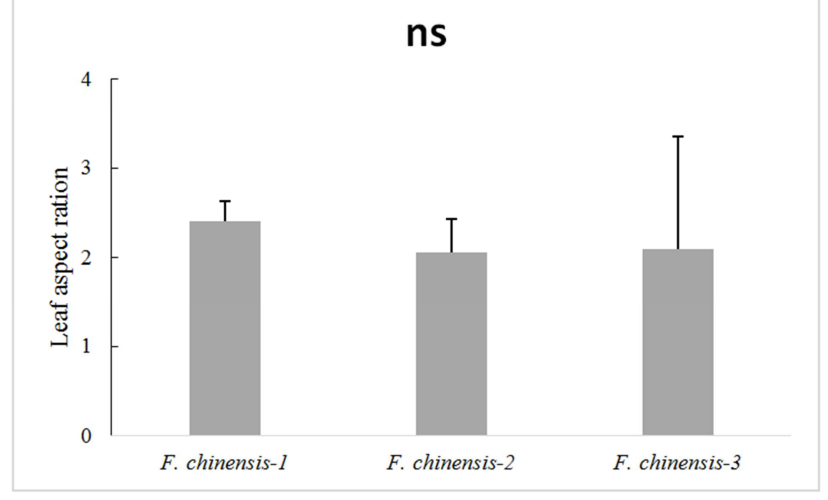

Figure 1. Main leaf morphological traits of Fraxinus chinensis plantation at different ages. Values are presented as mean $\pm S E$. Different letters denote significant differences at $p<0.05$ by Duncan's test.

\subsection{Comparison of Leaf Functional Traits in Different Layers of Plantation Community}

In Shouguang National Wetland Park, there are three levels of plant communities: tree (Plantation) - shrub (T. chinensis) grass. The average leaf area of tree layer and herb layer is more than $12 \mathrm{~cm}^{2}$, which is much higher than that of shrub layer. This is mainly because $T$. chinensis is the main shrub species in the park. As a primary shrub species, T. chinensis has typical scale leaves, which is obviously different from other woody and grass plants. The leaf aspect ration of tree layer and shrub layer is smaller than that of grass layer, which reflects the obvious difference of leaf morphological characters between woody plants and grass plants. 

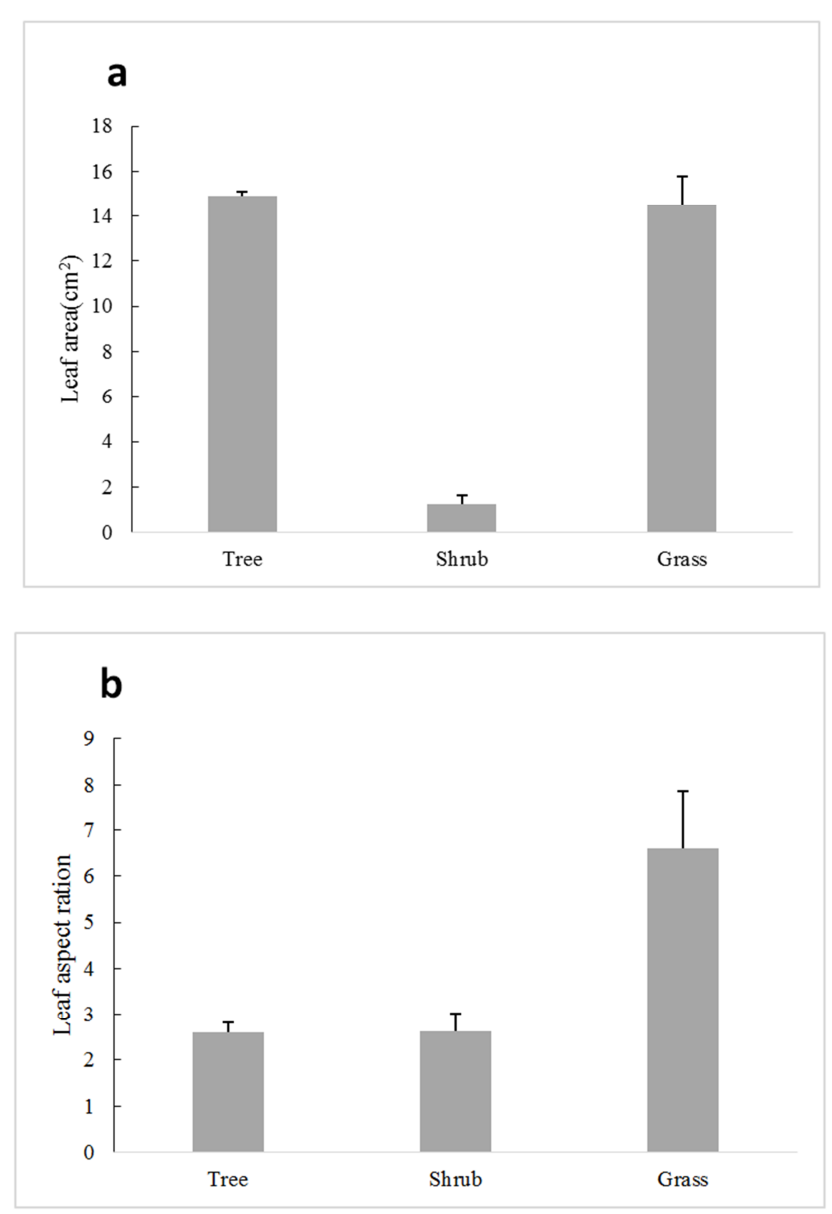

Figure 2. Main leaf morphological traits of plants in different layers. Values are presented as mean $\pm S E$.

\section{Discussion}

\subsection{Differences of Functional Traits Among Plants}

Through the study of ten kinds of plants in the investigated area, it was found that there were significant differences in the main leaf functional traits of these typical plants in the artificial forest community. The larger the area of leaf, the smaller leaf aspect ration. Plants occupy different niches through functional traits, and use sunlight, water and mineral nutrients at different levels to reduce interspecific competition, which is conducive to the survival of plants. The results showed that the leaf area decreased with the increase of stand age, and the leaf aspect ration increased with the increase of stand age. However, there was no significant difference in the traits among different forest ages, which indicated that the two functional traits of plants had little change in young and middle aged forests.

The results showed that the leaf area of trees and herbs was significantly larger than that of shrubs, and the leaf aspect ration of herbs was significantly larger than that of trees and shrubs. The trees are located in the top layer, receiving more sunlight, better light conditions, and larger leaves of trees, so as to obtain more nutrients for photosynthesis and maintain the good growth of trees. In addition, studies have shown that woody plants have high genetic stability, so the evolution rate of woody plants is lower than that of herbaceous plants, and the specific leaf mass of plants is significantly correlated with the growth type of plants $[3,11,12]$. Therefore, there are significant differences in leaf functional traits among different levels of plants.

\subsection{Adaptability Analysis of Plants to Salinization Stress Through Functional Traits}

Under saline stress, the change of plant morphological traits is the most intuitive expression. In general, plants will reduce transpiration by reducing leaf area to adapt to their physiological drought $[9,13]$. The total leaf area of several investigated species in the garden is also small, which is consistent with the general research conclusion. This paper mainly discusses the adaptation of plant leaf morphological traits to salinization stress. In addition, plants also show physiological adaptation to saline environment. T. chinensis in this study is a typical salt secreting plant, which can excrete a large amount of salt absorbed by plant roots through glands on the surface of plants, so that plants can carry out normal physiological activities [13-15].

\section{Conclusion}

In this study, ten species (Fraxinus chinensis, Ailanthus altissima, Sophora japonica, Populus tomentosa, Salix babylonica, Gleditsia sinensis, Tamarix chinensis, Sonchus oleraceus, Conyza Canadensis, Echinochloa crusgalli) were selected as the research objects to analyze their leaf area, leaf perimeter and leaf aspect ration, to explore the differences of functional traits among plants and their adaptation to saline environment. The results showed that there were significant differences in the main leaf functional traits among the artificial forest communities in the wetland park. The soil salinity also had an obvious effect on plant leaf traits. The differences of leaf traits among tree layer, shrub layer and grass layer were also very obvious. These differences in leaf traits are conducive to niche differentiation in plant communities, promote species coexistence and make full use of resources. There was no significant difference in leaf traits among individuals of different ages of the same tree species, and the relative stability was maintained.

\section{Acknowledgements}

The research was supported by National Science Foundation of China (No. 31500464).

\section{References}

[1] Meng, T. T., Ni, J. and Harrison, S. P. (2009). Plant morphometric traits and climate gradients in northern china: a meta-analysis using quadrat and flora data. Annals of Botany, 104(6): 1217-1229. 
[2] Craine, J. M., Lee, W. G., Bond, W. J., Williams, R. J. and Johnson, L. C. (2005). Environmental constraints on a global relationship among leaf and root traits of grasses. Ecology, 86: 12-19.

[3] Reich, P. B. (2014). The world-wide 'fast-slow' plant economics spectrum: a traits manifesto. Journal of Ecology, 102(2): 275-301.

[4] He, N. P., Liu, C. C., Zhang, J. H., Xu, L. and Yu, G. R. (2018). Perspectives and challenges in plant traits: From organs to communities. Acta Ecologica Sinica, 38(19): 6787-6796.

[5] Liu, X. J. and Ma, K. P. (2015). Plant Functional Traits - Concepts, Applications and Future Directions. Science in China (Series C), 45(04): 325-339.

[6] Chen, Y. T. and Xu, Z. Z. (2014). Review on research of leaf economics spectrum. Chinese Journal of Plant Ecology, 38(10): 1135-1153.

[7] Zhang, L. Y., Zhao, G. X., Xu, S. Y., Xu, D. F. and Wang, Z. H. (2005). Filtration of Suitable Saline-alkali Soil Amendments on Coastal Saline Soil. Journal of Soil and Water Conservation, 19(3): $21-23+28$.

[8] Liu, Y. J., Zhang, L. M. and Chen, B. M. (2011). Research Advances in Salt-Tolerance Evaluation and Plant Species Selection for Greening Purpose in the Coastal Saline-Alkaline Area. Journal of Southwest Forestry College, 31(3): 80-85.

[9] Chen, X., Liu, H. K., Zhao, C. Z., Wang, Q. and Wang, Y. P.
(2019). Responses of foliar anatomical traits to soil conditions in 11 tree species on coastal saline-alkali sites of Shandong, China. Chinese Journal of Plant Ecology, 43(8): 697-708.

[10] Wand, Q. Z., Liu, Q. G. and Xu, L. Y. (2017). Review on the mechanisms of the response to salinity-alkalinity stress in plants. Acta Ecologica Sinica, 37(16): 5565-5577.

[11] Villar, R., Merino, J. (2001). Comparison of leaf construction costs in woody species with differing leaf life spans in contrasting ecosystems. New Phytologist, 151: 213-226.

[12] He, Y. Y., Guo, S. L. and Wang, Z. (2019). Research progress of trade-off relationships of plant functional traits. Chinese Journal of Plant Ecology, 43(12): 1021-1035.

[13] Cui, B., Yang, Q., Zhang, K., Zhao, X. and You, Z. (2010). Responses of saltcedar (Tamarix chinensis) to water table depth and soil salinity in the yellow river delta, china. Plant Ecology, 209(2): 279-290.

[14] Zhao, Q. H., Ma, L. J., Liu, Q., Ding, S. Y., Tang, Q. and Liu, X. L. (2015). Plant species diversity and its response to environmental factors in typical river riparian zone in the middle and lower reaches of Yellow River. Chinese Journal of Ecology, 34(5): 1325-1331.

[15] Xi, M., Zhang, X. Y., Yuan, J. and Kong, F. L. (2012). Analysis of Projects and Measures for Wetland Preservation and Restoration in Shouguang Coastal Wetland National Park, Shangdong Province. Wetland Science, 10(03): 371-377. 